\title{
EVALUATION OF WETTING, STRUCTURAL AND THERMAL PROPERTIES OF ELECTROSPUN NANOFIBERS AT DIFFERENT PINEAPPLE LEAF FIBER / POLYETHYLENE TEREPHTHALATE RATIOS
}

\author{
Fatimah Muyassarah Abdul Aziz ${ }^{1}$ \\ https://orcid.org/0000-0002-6093-0336 \\ Siti Norasmah Surip ${ }^{1, \star}$ \\ https://orcid.org/0000-0001-8779-7275
}

Khairunnadim Ahmad Sekak

https://orcid.org/0000-0002-3847-8574

Mohd Khairun Anwar Uyup ${ }^{2}$

https://orcid.org/0000-0002-3787-9907

Mou'ad Ahmad Tarawneh ${ }^{3}$

https://orcid.org/0000-0002-0426-0972

Seng Hua Lee

https://orcid.org/0000-0001-6369-9902

\begin{abstract}
In this study, pineapple leaf fiber and polyethylene terephthalate electrospun nanofibers were produced via electrospinning process. Six ratios of pineapple leaf fiber/polyethylene terephthalate, namely $1 / 10 ; 1 / 7,5 ; 1 / 5$; $1 / 1$ and 1,3/1 were prepared and their wetting, structural and thermal properties were characterised. Wetting properties of this sample were studied using contact angle measurement. X-Ray Diffraction, differential scanning calorimetry and thermogravimetric analysis were conducted to get better understanding on the structural and its thermal properties, respectively. The results revealed that increasing the pineapple leaf fiber content simultaneously increased the ability of nanofibers to adsorb water as shown by lower contact angle degree with $81,6^{\circ}$ and adsorption time of 15 seconds. An increase in pineapple leaf fiber ratio did not change the peak position in X-Ray Diffraction and no new peaks observed for any sample. However, the peak at $23^{\circ}$ for samples with ratio $1 / 1$ and ratio $1,3 / 1$ exhibited higher intensity compared to that of pure polyethylene terephthalate. Thermal properties obtained from thermogravimetric analysis results suggested that thermal properties were not influenced by the pineapple leaf fiber ratio. Overall, pineapple leaf fiber/polyethylene terephthalate electrospun nanofibers produced at the ratio of $1 / 1$ displayed the optimum performance.
\end{abstract}

Keywords: Contact angle, electrospinning, nanofibers, pineapple leaf fiber, structural properties, wetting properties.

${ }^{1}$ Universiti Teknologi MARA, Faculty of Applied Sciences, Shah Alam, Selangor, Malaysia.

${ }^{2}$ Forest Research Institute Malaysia, Forest Product Division, Kuala Lumpur, Malaysia.

${ }^{3}$ Al-Hussein Bin Talal University, Department of Physics, Collage of Science, Ma'an, Jordan.

${ }^{4}$ Universiti Putra Malaysia, Institute of Tropical Forestry and Forest Products, Serdang, Selangor, Malaysia.

•Corresponding author: snorasmah@uitm.edu.my

Received: 18.02.2020 Accepted: 17.01.2021 


\section{INTRODUCTION}

Nano sized one dimensional (1-D) structures of fibers have been proposed to be able to further improve the performance of materials in many applications (Sridhar et al. 2015). Materials include natural polymers, synthetic polymers, carbon-based materials, semiconductor materials, and composite materials have found new remarkable properties of nanofibers form. Electrospun nanofibers have attracted much attention due to its potential in a variety of applications including drug delivery, tissue engineering, filtering in wastewater treatment and as a wound dressing (Yu et al. 2013, Sekar and Manickam 2019, Enizi et al. 2018).

In the recent years, synthetic fibers or petroleum-based materials are still being widely used owing to its good mechanical properties (Sridhar et al. 2015). For example, synthetic polyelectrolyte was often used as a water filter because of their effectiveness in coagulant aid. Unfortunately, most of them are not readily biodegradable which is harmful to the environment (Kawamura et al. 1991). Currently, scientists and engineers are actively searching for future materials that are bio-degradable, eco-friendly, and offer better properties.

Natural fiber has become an alternative source of material since it is abundantly available, cheap and most importantly environmentally friendly (Kang et al. 2013). Numerous researchs had been done in utilizing these natural fibers has successfully promoted the usage of ramie, jute fiber sisal fiber and pineapple plant for commercial purposes (Pickering et al. 2016). Pineapple leaf (PALF) which come from the secondary part of the plant (side product) during fruit harvesting have attracted much attention owing to its significant values (Neto et al. 2013).

PALF has high cellulose content and low lignin content, making it favorable in producing nanofibers (Chandramohan and Karimuthu, 2011). High cellulose content in PALF produced finer fiber compared to other natural fibers (Björquist et al. 2018). High cellulose content often leads to the improvement of the mechanical properties in the materials (Asim et al. 2018). This is due to the pack close arrangement of cellulose that is usually exposed after processing (Mello et al. 2014). There are many methods producing nanofibers and one of them is electrospinning. Electrospinning is well known for a simple, cheap and straightforward method that requires minimal supervision in producing nanofibers with diameters ranging from tenth to hundreds of nanometers (Wang et al. 2013). By using electrospinning method, ultrafine nanofibers thread was able to be smoothly drawn from a solution by electric force. Electrospinning which uses electric current as the main driving force can produce ultra-fine fibers that can reach $50 \mathrm{~nm}-200 \mathrm{~nm}$ nanoscale (Ahmed et al. 2015).

Recently, Mahardika et al. (2018) produced PALF fibers using a high-shear homogenization method. However, only fibers with diameter of $50 \mu \mathrm{m}$ were successfully produced. Up to now, there were no studies showing research on producing PALF nanofibers with diameter lower than $100 \mathrm{~nm}$. Besides, blending of natural fibers and synthetic fibers has been done before using sisal fiber/PET by the electrospinning method (Santos et al. 2019). This method has successfully produced nanofibers with size around $\sim 200 \mathrm{~nm}$.

Research on optimization of PALF electrospun nanofibers have been done previously (Aziz et al. 2018; Surip et al. 2018). Continuing from that findings, this study focuses on producing electrospun nanofibers by combining PALF with polyethylene terephthalate (PET) at different PALF/PET ratios. The properties of PALF/ PET electrospun nanofibers were characterized by using contact angle measurements (CA), water absorption, $\mathrm{X}$-Ray Diffraction (XRD), thermogravimetric analysis (TGA) and differential scanning calorimetry (DSC).

\section{MATERIALS AND METHODS}

\section{Materials}

PALF were received from a local Malaysia company in fibers form. Polyethylene terephthalate (PET) resin was obtained from Sigma-Aldrich and received in granular form with an average molecular weight $\left(\mathrm{M}_{\mathrm{v}}\right)$ of 18000. The chemicals were supplied by Aldrich Merck Company. Purity of Trifluoroacetic Acid (TFA) is 99\%, dichloromethane (DCM) is $99,8 \%$, cyclohexane is $99 \%$ and ethanol is $99,8 \%$.

\section{Dewaxing by soxhlet method}

PALF were dewaxed using soxhlet apparatus (Buchi, E-812, Flavil, Switzerland) to remove wax and ter- 
penes. This procedure was done to improve fibers' surface for better interface interaction. PALF were rinsed with $200 \mathrm{ml}$ of ethanol:cyclohexane at 1:1 ratio for 6 hours. The samples were rinsed using distilled water and oven dried (Memmert, BM 500, Schwabach, Germany) at $40^{\circ} \mathrm{C}$ for 12 hours.

\section{Dissolution of PALF and PET}

Dried PALF and PET were weighed accordingly as tabulated in Table 1. Five different concentrations were prepared for the electrospinning process. All samples were then diluted in the mixture of $5 \mathrm{~mL}$ and $6,5 \mathrm{~mL}$ of trifluoroacetic acid (TFA) and dichloromethane (DCM) solution respectively. The mixture was stirred for 6 hours until homogenous solution was obtained.

Table 1: Weight of PALF and PET for different ratio.

\begin{tabular}{|c|c|c|c|}
\hline Sample & $\begin{array}{c}\text { PALF } \\
(\mathrm{g})\end{array}$ & $\begin{array}{c}\text { PET } \\
(\mathrm{g})\end{array}$ & $\begin{array}{c}\text { Solvent (ml) } \\
\text { TFA/DCM (70:30) }\end{array}$ \\
\hline Pure PET & - & 0,45 & 5,0 \\
\hline Ratio1/10 & 0,06 & 0,60 & 5,0 \\
\hline Ratio1/7,5 & 0,06 & 0,45 & 5,0 \\
\hline Ratio1/5 & 0,06 & 0,30 & 5,0 \\
\hline Ratiol/1 & 0,10 & 0,10 & 6,5 \\
\hline Ratiol,3/1 & 0,20 & 0,15 & 6,5 \\
\hline
\end{tabular}

\section{Electrospinning}

Figure 1 illustrates the electrospinning machine set up in this study. As sufficient high voltage was supplied from the power supply, the electric charge will move into the solution through a metallic needle. High charge in solution causes solution instability thus forces the solution to move to different charge emitted from the metallic collector. Electrospinning parameters were set up at $12 \mathrm{kV} \sim 15 \mathrm{kV}$ of voltage $0,2 \mathrm{ml} / \mathrm{min}$ flow rate and $10 \mathrm{~cm}$ distance (Santos et al. 2019).

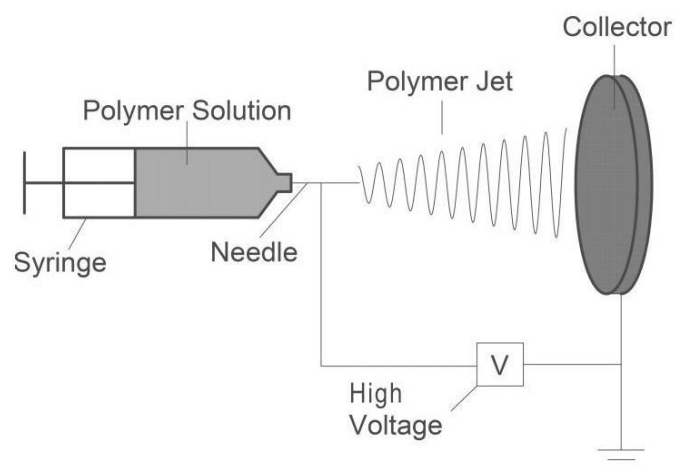

Figure 1: Electrospinning machine set up.

\section{Characterization}

\section{Wettability testing}

The wettability of the samples was tested using contact angle analyzer (goniometer AST/VCA -3000 s). The samples were cut into $2 \mathrm{~cm} \times 2 \mathrm{~cm}$ and placed on the test surface and a camera was used to capture the images. 3 microliters of purified water were gently dropped on the sample surface. Three replicates of contact 
angle were taken at different positions of the sample. The image of the water droplet was captured within each $5 \mathrm{~s}$ of delivery until $40 \mathrm{~s}$ (Goetz et al. 2016).

In the case of complete wetting, the contact angle is $0^{\circ}$. Between $0^{\circ}$ and $90^{\circ}$, the solid is wettable and above $90^{\circ}$ is not wettable. In the case of superhydrophobic materials with the so-called lotus effect, the contact angle approaches the theoretical limit of $180^{\circ}$.

\section{Water absorption}

Water absorption (WA) testing was used to determine the moisture absorption of nanofibers. Increasing in water absorption without disrupting the physical bond will produce fibers with great absorbing ability.

WA test was conducted according to ASTM D570-98 (2018). Two replicates of each ratio were soaked into distilled water for 24 hours. Final weight of the samples was recorded. The percentages were calculated using Equation 1.

$$
\frac{W_{m}-W_{0}}{W_{m}} \times 100
$$

$W m$ : weight of sample after soak

Wo: initial weight

\section{X-Ray diffraction (XRD)}

Nanofiber electrospun mats were cut into several mats of $3 \mathrm{~cm} \times 3 \mathrm{~cm}$ of rectangular shape and carefully placed in the sample slot. The XRD patterns for the samples were recorded at room temperature from $2 \theta=50$ to 800 (degrees) by X-ray diffractometer (PANalytical X'Pert PRO) using CuKa radiation $(\lambda=1,5418 \AA$ ). The XRD measurements were performed at a scanning speed of 2,50 degrees per minute. The results were drafted using Origin Pro 8.1 (2018) Origin software and the crystallite size and the percentage of crystallinity were determined using Equation 2 and Equation 3 respectively.

$$
d=\left(\frac{k \lambda}{\beta \cos \theta}\right)
$$

Crystallite size,

Where:

$\mathrm{d}=$ Crystallite size

$\mathrm{K}=$ Scherrer constant $(0,94)$

$\lambda=\mathrm{X}$-ray wavelength $(0,1542 \mathrm{~nm})$

$\beta=$ width of the peak (FWHM)

$\theta=$ Bragg's angle

Crystallinity: 


\section{$\frac{\text { Area of crystalline }}{\text { Area of amorphous }+ \text { Area of crystalline }} \times 100$}

\section{Thermo gravimetric analysis (TGA)}

TGA analysis were carried out using thermogravimetric analyser (Netzch Tg $200 \mathrm{~F} 3$ Tarsus). The samples were then heated from room temperature to $800{ }^{\circ} \mathrm{C}$ at a heating rate of $10^{\circ} \mathrm{C} / \mathrm{min}$ under nitrogen gas. The crucible used was an aluminium pan. The results were analysed using NATZCH software to obtain degradation temperature, dTG graph, residual mass and percentage mass loss.

\section{Differential scanning calorimetry (DSC)}

DSC analysis was carried out using Differential Scanning Calorimetry analyser (Netzch Dsc 200 F3 Tarsus). The samples about $5 \mathrm{mg}$ were heated from room temperature to $800{ }^{\circ} \mathrm{C}$ at a heating rate of $10{ }^{\circ} \mathrm{C} / \mathrm{min}$ under nitrogen gas. The crucible used was a closed lid aluminium pan. The obtained results were analysed using NATZCH software to determine the glass transition temperature, melting temperature and crystalline temperature.

\section{RESULTS AND DISCUSSION}

\section{Wetting properties of PALF/PET electrospun nanofibers}

Wetting properties of nanofibers is one of the most important properties for surface interaction. Contact angle (CA) measurement was carried out to study the wetting properties of electrospun PALF/PET mat. The CA values of electrospun nanofibers at different PALF:PET ratios are tabulated in Table 2. From the table, pure PET displayed the highest CA which is $148,17^{\circ}$. The CA values decreased with increasing ratio of PALF. At the ratio of $1 / 10$ (PALF/PET), the CA value of the mat was recorded at $117,25^{\circ}$ and drastically dropped to the lowest $\mathrm{CA}$ of $27,76^{\circ}$ at the ratio of $1,3 / 1$. The reduction of surface CA was due to the existence of polar chemical groups on the PET surface after the addition of PALF. As a result, the surface energy of the samples was enhanced and led to lower surface CA.

Table 2: Average Water Contact Angle (WCA) values after 1 second water drop.

\begin{tabular}{|c|c|}
\hline $\begin{array}{c}\text { Sample/Water } \\
\text { Contact Angle }\left({ }^{\circ}\right)\end{array}$ & $\begin{array}{c}\text { Average WCA } \\
\text { at 1 second }\end{array}$ \\
\hline Pure PET & 148,17 \\
\hline Ratio 1/10 & 117,30 \\
\hline Ratio 1/7,5 & 95,95 \\
\hline Ratio 1/5 & 89,04 \\
\hline Ratio 1/1 & 85,22 \\
\hline Ratio 1,3/1 & 27,76 \\
\hline
\end{tabular}

Figure 2 displays the change of CA over time (s) on pure PET and PALF/PET electrospun nanofibers at different PALF/PET ratios. As can be seen from the figure, the CA of the pure PET and mats at 1/10 remained static even after several seconds, indicating that the surfaces of both materials are not absorbing any water molecule or hydrophobic. Meanwhile, samples with ratio $1 / 7,5 ; 1 / 5 ; 1 / 1$ and $1,3 / 1$ showed decreases in CA values at different rates as the time taken for the CA values to achieve $0^{\circ}$ differed between samples. As the 
ratio of PALF increased, the time needed for the water droplet to reach $0^{\circ}$ is shortened. At a PALF/PET ratio of $1,3 / 1$, it only required $10 \mathrm{~s}$ for the water droplet to be fully absorbed by the nanofibers.

By increasing the PALF content, the CA values show a decreasing trend indicating that PALF addition changed the properties of the nanofibers from hydrophobic to be more hydrophilic. Water drop becomes more easily absorbed through the decreasing in fiber size and due to the high O-H bonding that can react with water (Hekmati et al. 2014). Synthetic polymers with hydrophobic nature of the electrospun materials have limited its application and efficiency (Goetz et al. 2016). To overcome this problem, a strategy of blending together both natural and synthetic polymers was adopted. Hydrophobic properties of PET were modified to become more water absorbent due to the presence of PALF cellulosic materials. This result was supported by Goetz et al. (2016) that studied on the potential of chitosan as natural fibers to become super hydrophilic materials for water filtration.

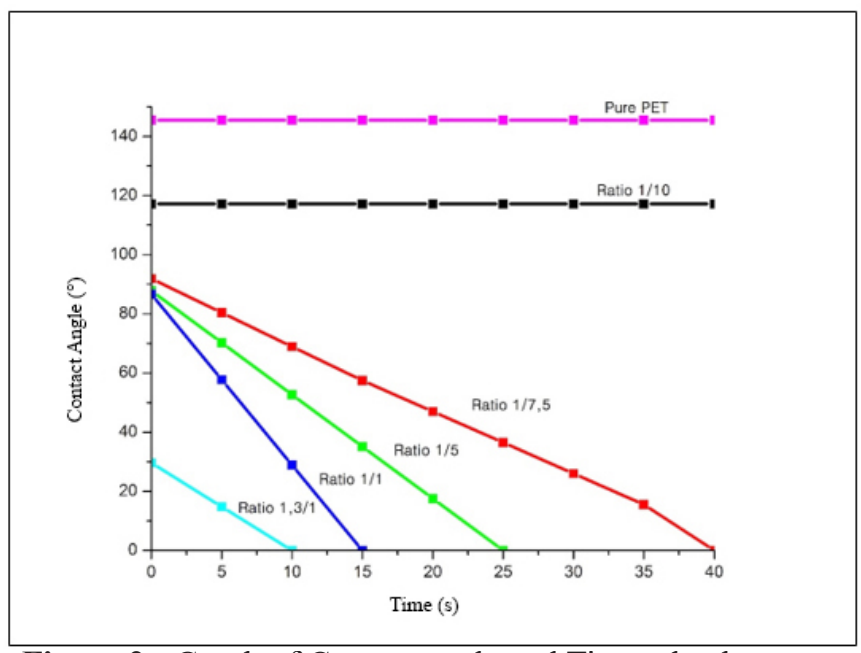

Figure 2: Graph of Contact angle and Time adsorb.

\section{Water absorption (WA)}

From the application point of view, it is important to know the behaviour of the PALF/PET electrospun in water. For this purpose, PALF/PET samples were soaked in water for 24 hours and its water absorption were observed. Figure 3 shows the results of the water uptake percentage for PALF/PET sample at different ratios. Pure PET shows the lowest percentage of water uptake which is $23,4 \%$. It is probably due to its fiber size and hydrophobicity property. PALF has been known as a highly hygroscopic material due to its high cellulose content (Aji et al. 2013). Therefore, addition of PALF undoubtedly increased the water uptake of the electrospun nanofibers. From Figure 3, it can be seen that the water absorption increased along with increasing PALF ratio. It is interestingly to note that a significant increment in water absorption was observed in sample with ratio of $1 / 5$ compared to that of sample with ratio of $1 / 7,5$. The increment in water absorption was more than two-folds ( $72 \%$ in sample with ratio of $1 / 7,5$ and $162 \%$ in samples with ratio of $1 / 5)$. This is probably due to the decreases in the nanofiber diameter which is from $120 \mathrm{~nm}$ to $46 \mathrm{~nm}$ as shown in Table 3 . Table 3 shows the average diameter of nanofibers. The SEM micrographs in Figure 4 shows the image of nanofibers mat at $20 \mathrm{k}$ magnification for ratios of 1/7,5 and 1/5. Small diameter of fiber also led to an increase in pore size of nanofibers thus allowing a higher amount of water to be adsorbed (Hekmati et al. 2014). Sample ratio 1/10 and sample ratio 1/7,5 shows bigger diameter, due to the different solubility and the dielectric constant of the PET and PALF (Jung et al. 2007). Increasing in PALF ratio had narrowed the fiber diameter distribution.

As expected, the percentage of water uptake increases steadily as the ratio of PALF increases until it reaches the saturated level. Further increasing the PALF ratio did not resulted in much difference on the water absorption percentage. This is possibly due to it having reached the maximum absorption capacity. These findings proved that degradation of PALF, which can lead to dissolution, had not occurred during this time period and under these conditions. 


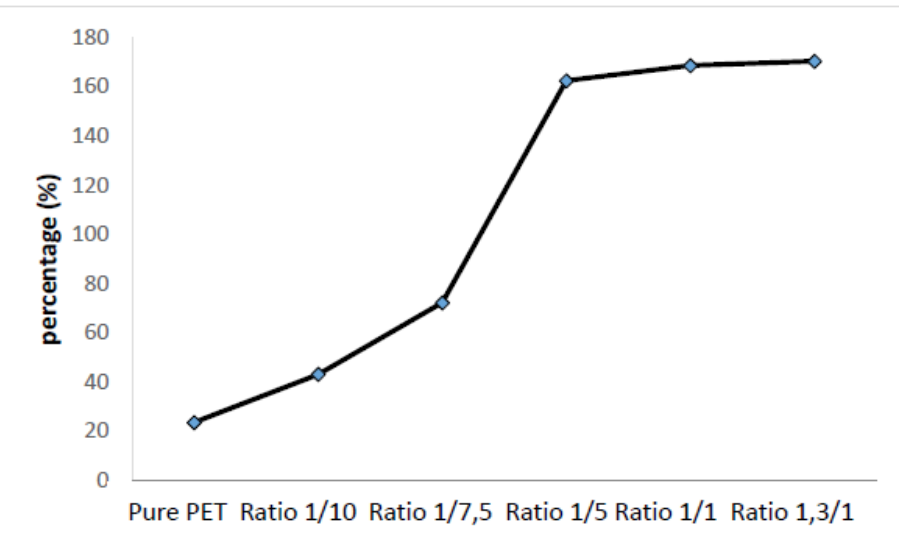

Figure 3: Percentage of water uptake of electrospun nanofibers mat made from different PALF/PET ratios.
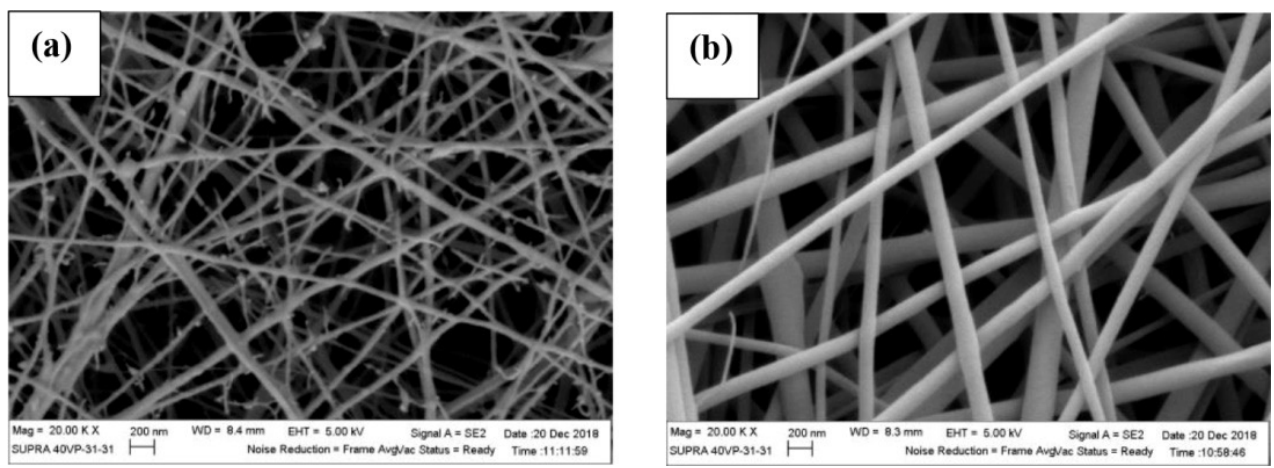

Figure 4: FESEM micrographs of PALF/PET nanofibers (a) ratio 1/5 (b) ratio 1/7,5.

Table 3: Diameter size of electrospun nanofibers.

\begin{tabular}{|c|c|}
\hline Sample (PALF/PET) & Average Diameter $(\mathrm{nm})$ \\
\hline Pure PET & $96,379 \pm 34$ \\
\hline Ratio 1/10 & $93,214 \pm 28$ \\
\hline Ratio 1/7,5 & $120,915 \pm 41$ \\
\hline Ratio 1/5 & $46,263 \pm 16$ \\
\hline Ratio 1/1 & $57,31 \pm 17$ \\
\hline Ratio 1,3/1 & $43,629 \pm 10$ \\
\hline
\end{tabular}

\section{X-Ray Diffraction (XRD)}

Figure 5 shows the XRD result obtained for each sample. The diffraction peaks for Pure PET were observed at $2 \theta=16^{\circ}$ and $2 \theta=23^{\circ}$ in which the peak at $23^{\circ}$ is moderately sharp and the other peak is broader. The peaks observed were in agreement with the previous study by Mahar et al. (2017) who suggested that the observed patterns were similar to that of semicrystalline structure of PET. Sharp peak is usually attributed to crystalline structure while broader peak is attributed to amorphous structure (Mahar et al. 2017). According to Mahardika et al. (2018), PALF also exists with semi crystalline structure with broad peak at $2 \theta=18^{\circ}$ and 
sharp peak at $2 \theta=22,6^{\circ}$.

An Increase in PALF ratio did not change the peak position angle, indicating that the sample still exhibits the same structure as pure PET and pure PALF. There are no new peaks observed for any sample. However, the peak at $23^{\circ}$ for samples with ratio $1 / 1$ and ratio $1,3 / 1$ has higher intensity compared to that of pure PET peak. According to Karuppuchamy and Jeong (2005), hydrophilic materials with high crystallinity produced materials that come with long durability and good absorbing abilities. These properties are said to be beneficial to applications such as biomedical and water treatment (Alharbi et al. 2016).

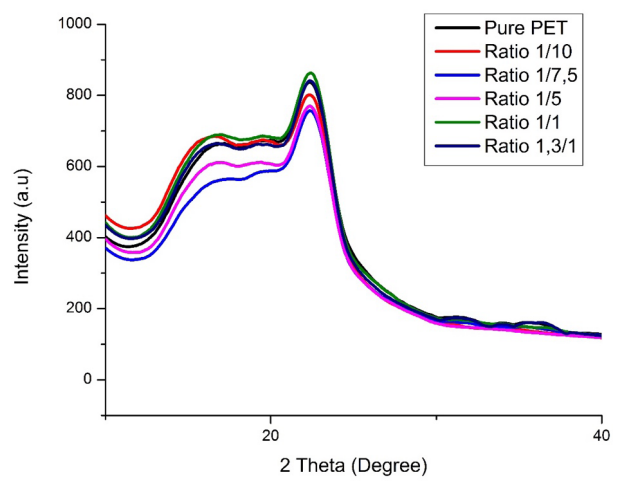

Figure 5: XRD diffactograms for PET and PALF/PET electrospun nanofibers.

\section{Thermogravimetric analysis (TGA)}

The TGA or thermal profile testing is aimed to uncover the thermal stability of the materials. Figure 6 shows TGA graph for pure PET electrospun and PALF/PET electrospun samples with different ratios. Pure PET sample shows single step degradation which occurred at temperature of $369,7^{\circ} \mathrm{C}$. This was in agreement with Mahar et al. (2017) who mentioned that degradation of PET electrospun usually occurred at temperature between $350{ }^{\circ} \mathrm{C}$ to $400{ }^{\circ} \mathrm{C}$.

In addition, one step degradation proved that water is absent in PET which usually caused slope degradation at temperature below $100{ }^{\circ} \mathrm{C}$. However, the degradation peak increased along with PALF addition. As can be seen from Figure 6, nanofibers with addition of PALF exhibit additional stages of decomposition due to the presence of PALF. Due to the hygroscopicity of the PALF, an initial weight loss could be observed in the samples with different PALF ratios. The weight loss was corresponding to the evaporation of water and volatile organic compounds in PALF (Lee et al. 2018).

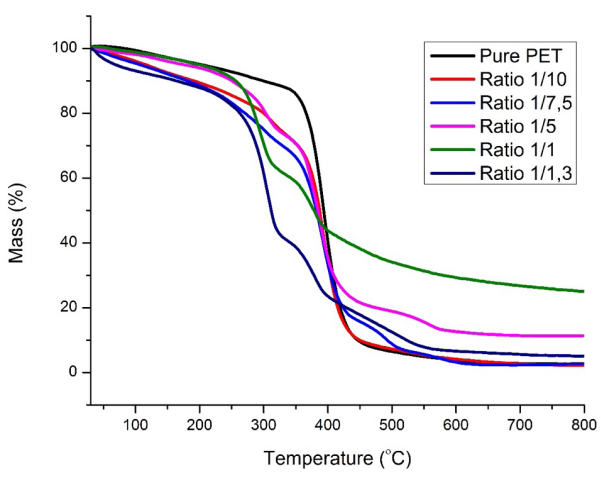

Figure 6: TGA of electrospun nanofibers mat made from different PALF/PET ratios. 
Increasing in PALF ratio showed new peak degradation with increasing mass change at temperature 260 ${ }^{\circ} \mathrm{C}-320{ }^{\circ} \mathrm{C}$ (cellulose degradation) and at temperature $360{ }^{\circ} \mathrm{C}-400{ }^{\circ} \mathrm{C}$ (lignin degradation). The data obtained from the graph were tabulated in Table 4. Sample with PALF shows initial degradation temperature (IDT) which is approximately around $200{ }^{\circ} \mathrm{C}-280^{\circ} \mathrm{C}$ compared to pure PET at $369,7{ }^{\circ} \mathrm{C}$ due to the presence of hemicellulose and cellulose that has lower thermal resistance (Sridhar et. al. 2015). This is supported by Neto et al. (2013) who indicated that cellulose degradation temperature occurred at around $\sim 260{ }^{\circ} \mathrm{C}$. According to Adam et al. (2018), cellulose content together with hemicellulose will play a profound effect on fiber strength and self resinification of fiber during exposure to high temperature and pressure.

Addition of PALF in PET does not really affect much on PET degradation temperature which is around $370{ }^{\circ} \mathrm{C}-390{ }^{\circ} \mathrm{C}$. A peak which is at high temperature at $480{ }^{\circ} \mathrm{C}-510^{\circ} \mathrm{C}$ represents the lignin degradation where lignin with strong hydrogen bond is well known for its high thermal stability up to $600{ }^{\circ} \mathrm{C}$ (Dorez et al. 2013). This peak was absent for the pure PET sample and sample ratio $1 / 10$ due to lower amount of PALF in the sample.

Table 4: Data Summarize of TGA for PET and PALF/PET electrospun nanofibers.

\begin{tabular}{|c|c|c|c|c|}
\hline \multirow{2}{*}{ Sample } & \multirow{2}{*}{ IDT } & \multicolumn{3}{|c|}{ DTG Temp/ RD } \\
\cline { 3 - 5 } & & $1^{\text {st }}$ Peak & $2^{\text {nd }}$ Peak & $3^{\text {rd }}$ peak \\
\hline Pure PET & 369,7 & - & 369,7 & - \\
\hline Ratio 1/10 & 279,7 & 279,7 & 388,3 & - \\
\hline Ratio 1/7,5 & 254,2 & 254,2 & 392,2 & 484,3 \\
\hline Ratio 1/5 & 268,2 & 268,2 & 386,4 & 553,8 \\
\hline Ratio 1/1 & 265,7 & 265,7 & 378,9 & 534,5 \\
\hline Ratio 1,3/1 & 234,1 & 234,1 & 379,9 & 507,3 \\
\hline
\end{tabular}

\section{Differential scanning calorimetry (DSC)}

Differential scanning calorimetry, DSC analyses were carried out. Through this analysis, the glass transition temperature, melting temperature and crystalline temperature were determined. The thermal profiles of the samples were shown in Figure 7. Data obtained from the DSC were summarized in Table 5. According to Nadirah et al. (2011), PALF exhibits $\mathrm{T}_{\mathrm{m}}=290^{\circ} \mathrm{C}$ but does not produce any peak for $\mathrm{T}_{\mathrm{g}}$ and $\mathrm{T}_{\mathrm{c}}$, while PET shows $\mathrm{T}_{\mathrm{g}}$ at around $58^{\circ} \mathrm{C}$ and two melting point at $221^{\circ} \mathrm{C}$ and $253^{\circ} \mathrm{C}$ respectively.

Glass transition temperature, $\mathrm{T}_{\mathrm{g}}$ occurred at temperature range $55^{\circ} \mathrm{C}-57^{\circ} \mathrm{C}$ for all the samples except for ratio $1 / 1$ and ratio $1,3 / 1$ where $\mathrm{T}_{\mathrm{g}}$ value shifted to higher temperature at $63{ }^{\circ} \mathrm{C}$ and $59{ }^{\circ} \mathrm{C}$ respectively. Increasing $\mathrm{T}_{\mathrm{g}}$ values indicate that the sample becomes more crystalline in its structure. This result was supported by ${ }^{\mathrm{g}} \mathrm{XRD}$ results that show sample ratio $1 / 1$ and $1,3 / 1$ exhibit high crystallinity compared to pure PET.

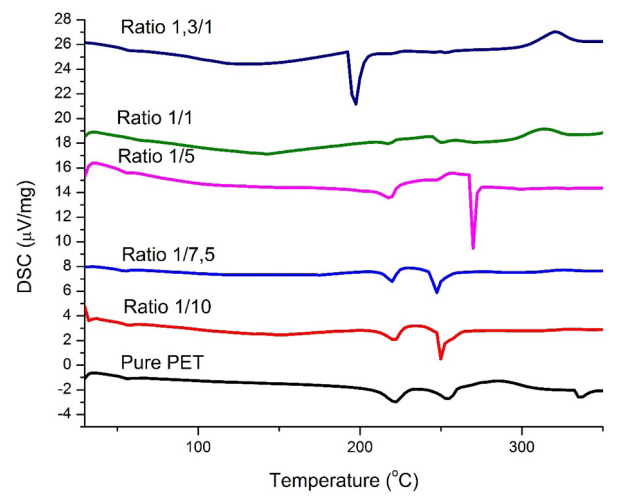

Figure 7: DSC Thermogram of electrospun nanofibers mat made from different PALF/PET ratios. 
Two melting temperatures were shown for pure PET which is at $221^{\circ} \mathrm{C}$ and $253{ }^{\circ} \mathrm{C}$ respectively. Two different melting point is associated with different melting of the lamellae layer (Kong et al. 2003). From the graph, the melting temperature for PET was undetected for sample ratio 1,3/1 due to the insufficient quantity of PET. This further highlights the presence of PALF as represented by its melting point, $\mathrm{T}_{\mathrm{m}}$ at $196,2^{\circ} \mathrm{C}$.

Table 5: Summarized data of DSC for PET and PALF/PET electrospun nanofibers.

\begin{tabular}{|c|c|c|c|}
\hline Samples & $\mathrm{T}_{\mathrm{g}}\left({ }^{\circ} \mathrm{C}\right)$ & $\mathrm{T}_{\mathrm{m} 1}\left({ }^{\circ} \mathrm{C}\right)$ & $\mathrm{T}_{\mathrm{m} 2}\left({ }^{\circ} \mathrm{C}\right)$ \\
\hline Pure PET & 56,2 & 221,7 & 253,7 \\
\hline Ratio 1/10 & 55,5 & 218,7 & 246,5 \\
\hline Ratio 1/7,5 & 55,9 & 219,6 & 246,2 \\
\hline Ratio 1/5 & 56,6 & 218,9 & 269,2 \\
\hline Ratio 1/1 & 62,0 & 217,5 & 250,4 \\
\hline Ratio 1,3/1 & 58,6 & - & 196,2 \\
\hline
\end{tabular}

\section{CONCLUSIONS}

PALF/PET nanofibers were prepared at various ratios by electrospinning method and its properties were examined. Pure PET shows larger diameter of fibers and the size was decreased by increasing PALF content. Introducing PALF also change the wetting properties of the nanofibers. A significant increment in water absorption percentage was seen for sample ratio $1 / 5$ which could be attributed to the reduction in fiber size. The increment in PALF ratio did not change the peak position in XRD and no new peaks was observed for any sample. However, the peak at $23^{\circ}$ for samples with ratio $1 / 1$ and ratio $1,3 / 1$ showed higher intensity compared to that of pure PET. In term of thermal properties, addition of PALF led to early degradation of the nanofibers as a result of degradation of thermally labile hemicellulose and cellulose content in PALF. However, there is no significant influence of the PALF ratio in the final thermal stability of the produced nanofibers. Glass transition temperature, $\mathrm{T}_{\mathrm{g}}$ occurred at temperature range $55^{\circ} \mathrm{C}-57^{\circ} \mathrm{C}$ for all the samples except for ratio $1 / 1$ and ratio $1,3 / 1$ where $\mathrm{T}_{\mathrm{g}}$ value shifted to higher temperature at $63{ }^{\circ} \mathrm{C}$ and $59^{\circ} \mathrm{C}$, respectively. Introducing PALF to PET have been demonstrated to alter its properties especially in fiber size and wetting properties. Overall, electrospun nanofibers produced at PALF/PET ratio of $1 / 1$ exhibited the optimum performance compared to that of its counterparts.

\section{ACKNOWLEDGMENTS}

The authors would like to acknowledge the Faculty of Applied Sciences and Institute of Science, Universiti Teknologi MARA for providing research facilities. This research was funded by GIP Grant no: 600-IRMI/ MyRA 5/3/GIP (073/2017)

\section{REFERENCES}

Adam, A.B.A.; Basta, A.H.; El-Saied, H. 2018. Evaluation of Palm Fiber Components an Alternative Biomass Waste for Medium Density Fibreboard Manufacturing. Maderas-Cienc Tecnol 20(4): 579-594. http://dx.doi.org/10.4067/S0718-221X2018005004601

Ahmed,F.E.; Lalia, B.S.; Hashaikeh, R. 2015. A review on electrospinning for membrane fabrication: Challenges and applications. Desalination 356: 15-30. https://doi.org/10.1016/j.desal.2014.09.033

Aji, I.; Zainudin, E.; Abdan, K.; Sapuan, S.; Khairul, M. 2013. Mechanical properties and water absorption behavior of hybridized kenaf/pineapple leaf fibre-reinforced high-density polyethylene composite. $J$ 
Compos Mater 47(8): 979-990. https://doi.org/10.1177/0021998312444147

Alharbi, A.R.; Alarifi, I.M.; Khan, W.S.; Asmatulu, R. 2016. Highly hydrophilic electrospun polyacrylonitrile/polyvinypyrrolidone nanofibers incorporated with gentamicin as filter medium for dam water and wastewater treatment. J Memb Separ Tech 5(2): 38-56. http://www.lifescienceglobal.com/pms/index.php/jmst/ article/view/3966

ASTM. 2018. Standard Test Method for Water Absorption of Plastics. ASTM. D570-98. 2018. ASTM International: West Conshohocken, PA, USA.

Asim, M.; Jawaid, M.; Abdan, K.; Ishak, M.R. 2018. The Effect of Silane Treated Fibre Loading on Mechanical Properties of Pineapple Leaf/Kenaf Fibre Filler Phenolic Composites. J Polym Environ 26: 15201527. https://doi.org/10.1007/s10924-017-1060-z

Aziz, F.M.; Surip, S.N.; Bonnia, N.N.; Sekak, K.A. 2018. The effect of Pineapple Leaf Fiber (PALF) incorporation into Polyethylene Terephthalate (PET) on FTIR, morphology and wetting properties. IOP Conf Ser: Earth Environ Sci 105(012082). https://doi.org/10.1088/1755-1315/105/1/012082

Björquist, S.; Aronsson, J.; Henriksson, G.; Persson, A. 2018. Textile qualities of regenerated cellulose fibers from cotton waste pulp. Textile Research Journal 88(21): 2485-2492. https://doi.org/10.1177/0040517517723021

Chandramohan, D.; Karimuthu, K. 2011. A Review on Natural Fibers. Int J Recent Res 8(2): 194-204. https://www.arpapress.com/Volumes/Vol8Issue2/IJRRAS_8_2_09.pdf

Dorez, G.; Taguet, A.; Ferry, L.; Lopez-Cuesta, J.M. 2013. Thermal and fire behavior of natural fibers/PBS biocomposites. Polym Degrad Stabil 98(1): 87-95. https://doi.org/10.1016/j.polymdegradstab.2012.10.026

Enizi, A.M.; Zhago, M.M.; Elzatahry, A.A. 2018. Polymer-Based Electrospun Nanofibers for Biomedical Applications. J Nanomater 8(4):259. https://doi.org/10.3390/nano8040259

Goetz, L.A.; Jalvo, B.; Rosal, R.; Mathew, A.P. 2016. Superhydrophilic anti-fouling electrospun cellulose acetate membranes coated with chitin nanocrystals for water filtration. J Membrane Sci 510: 238-248. https://doi.org/10.1016/j.memsci.2016.02.069

Hekmati, A.H.; Khenoussi, N.; Nouali, H.; Patarin, J.; Drean, J.Y. 2014. Effect of nanofiber diameter on water absorption properties and pore size of polyamide-6 electrospun nanoweb. Textile Research Journal, 84(19): 2045-2055. https://doi.org/10.1177/0040517514532160

Jung, K.H.; Huh, M.W.; Meng, W.; Yuan, J.; Hyun, S.H.; Bae, J.S.; Kang, I.K. 2007. Preparation and antibacterial activity of PET/chitosan nanofibrous mats using an electrospinning technique. $J$ Appl Polym Sci 105(5): 2816-2823. https://doi.org/10.1002/app.25594

Kang, Y.; Ahn, Y.; Lee, S.H.; Ku, M.K.; Kim, H. 2013. Lignocellulosic Nanofiber Prepared by Alkali Treatment and Electrospinning Using Ionic Liquid. Fibers Polym 14(4): 530-536. https://link.springer.com/ article/10.1007/s12221-013-0530-8

Karuppuchamy, S.; Jeong, J.M. 2005. Super-hydrophilic amorphous titanium dioxide thin film deposited by cathodic electrodeposition. Mater Chem Phys 93(2-3): 251-254. https://doi.org/10.1016/j. matchemphys.2005.04.015

Kawamura, S. 1991. Effectiveness of natural polyelectrolytes in water treatment. Journal-American Water Works Association 83(10): 88-91. https://doi.org/10.1002/j.1551-8833.1991.tb07236.x

Kong, Y.; and Hay, J.N. 2003. The enthalpy of fusion and degree of crystallinity of polymers as measured by DSC. European Polymer Journal 39(8): 1721-1727. https://doi.org/10.1016/S0014-3057(03)00054-5

Lee, S.H.; Ashaari, Z.; Ang, A.F.; Halip, J.A.; Lum, W.C.; Dahali, R.; Halis, R. 2018. Effects of twostep post heat-treatment in palm oil on the properties of oil palm trunk particleboard. Ind Crop Prod 116: 249258. https://doi.org/10.1016/j.indcrop.2018.02.050 
Mahar, F.K.; Mehdi, M.; Qureshi, U.A.; Brohi, K.M.; Zahid, B.; Ahmed, F.; Khatri, Z. 2017. Dyeability of recycled electrospun polyethylene terephthalate (PET) nanofibers: Kinetics and thermodynamic study. J Mol Liq 248: 911-919. https://doi.org/10.1016/j.molliq.2017.10.116

Mahardika, M.; Abral, H.; Kasim, A.; Arief, S.; Asrofi, M. 2018. Production of Nanocellulose from Pineapple Leaf Fibers via High-Shear Homogenization and Ultrasonication. Fibers 6(2): 28. https://doi.org/10.3390/fib6020028

Mello, E.; Ribellato, C.; Mohamedelhassan, E. 2014. Improving Concrete Properties with Fibers Addition. Int J Civ Eng 8(3): 249-254. https://publications.waset.org/9997631/improving-concrete-properties-with-fibers-addition

Nadirah, W.W.; Jawaid, M.; Al Masri, A.A.; Khalil, H.A.; Suhaily, S.S.; and Mohamed, A.R. 2012. Cell wall morphology, chemical and thermal analysis of cultivated pineapple leaf fibres for industrial applications. Journal of Polymers and the Environment 20(2): 404-411. https://doi.org/10.1007/s10924-011-0380-7

Neto, A.R.S.; Araujo, M.A.M.; Souza, F.V.D.; Mattoso L.H.C.; Marconcini, J.M. 2013. Characterization and comparative evaluation of thermal, structural, chemical, mechanical and morphological properties of six pineapple leaf fiber varieties for use in composites. Ind Crop Prod 43: 529- 537. https://doi.org/10.1016/j. indcrop.2012.08.001

OriginPro Software. 2018. Origin Pro version 8.1. OriginLab Corporation: USA. https://www.originlab. com/

Pickering, K.L.; Effendy, M.G.A.; Lee, T.M. 2016. A review of recent developments in natural fibre composites and their mechanical performance. Compos Part A-Appl S 83: 98-112. https://doi.org/10.1016/j. compositesa.2015.08.038

Sekar, A.D.; Manickam, M. 2019. Current Trends of Electrospun Nanofibers in Water and Wastewater Treatment. In: Water and Wastewater Treatment Technologies. Energy, Environment, and Sustainability. Bui, X.T.; Chiemchaisri, C.; Fujioka, T.; Varjani, S. (eds.). Springer: Singapore. https://doi.org/10.1007/978-98113-3259-3_21

Sridhar, R.; Lakshmirayanan, R.; Madhaiyan, K.; Barathi, V.A.; Lim, K.H.C.; Ramakrishna, S. 2015. Electrosprayed nanoparticles and electrospun nanofibers based on natural materials: applications in tissue regeneration, drug delivery and pharmaceuticals. Chem Soc Rev 44(3): 790-814. https://doi.org/10.1039/ C4CS00226A

Surip, S.N.; Abdul-Aziz, F.M.; Bonnia, N.N.; Sekak, K.A. 2018. Effect of Pineapple Leaf Fibers (PALF) concentration on nanofibers formation by electrospinning. IOP Conf Ser Mater Sci Eng 290(1): 1-6. https://doi.org/10.1088/1757-899X/290/1/012003

Wang, X.; Ding, B.; Sun, G.; Wang, M.; Yu, J. 2013. Electro-spinning/netting: A strategy for the fabrication of three-dimensional polymer nano-fiber/nets. Prog Mater Sci 58: 1173-1243. https://doi.org/10.1016/j. pmatsci.2013.05.001

Yu, D.G.; Wang, X.; Li, X.Y.; Chian, W.; Li, Y.; Liao, Y.Z. 2013. Electrospun biphasic drug release polyvinylpyrrolidone/ethyl cellulose core/sheath. Acta Biomater 9(3): 5665-5672. https://doi.org/10.1016/j. actbio.2012.10.021 